\title{
Estrutura, Agência e Interpretação: Elementos para uma Abordagem Recursiva do Processo de Institucionalização
}

\section{Unlocking the Institutionalization Process: Insights for an Institutionalizing Approach}

Clóvis L. Machado-da-Silva

Ph.D. em Estudos Organizacionais e Estratégia pela Michigan State University, EUA. Professor Titular do CEPPAD/UFPR e Professor do PMDA/UP, Curitiba/PR, Brasil.

Valéria Silva da Fonseca *

Doutora em Engenharia de Produção pela UFSC. Professora Adjunta do PPAD/PUCPR, Curitiba/PR, Brasil.

João Marcelo Crubellate Doutor em Administração de Empresas pela EAESP/FGV. Professor do DAD/UEM, Maringá/PR, Brasil.

* Endereço: Valéria Silva da Fonseca

Pontifícia Universidade Católica do Paraná, Escola de Negócios, Programa de PósGraduação em Administração, Rua Imaculada Conceição, 1155, Bloco Acadêmico, $1^{\circ}$ andar, Prado Velho, Curitiba/PR, 80215-901.E-mail: vsf29@ hotmail.com

Este artigo foi originalmente publicado na Brazilian Administration Review - BAR, v. 2, n. 1, January - June, 2005, disponível no endereço www.anpad.org.br/bar. 


\title{
Resumo
}

A teoria neo-institucional tem sido caracterizada por alguns estudiosos do campo dos estudos organizacionais como uma abordagem supostamente determinística. Demonstramos no presente ensaio teórico que tal caracterização não pode ser impingida à perspectiva neo-institucional de maneira generalizada, mas apenas a uma leitura dicotômica dela, típica de visões monoparadigmáticas do processo de institucionalização. A partir dessa demonstração, defendemos a idéia da teoria institucional como teoria multiparadigmática. Para tanto, apresentamos argumentos em favor de uma abordagem recursiva do processo de institucionalização, ressaltando que as noções de estrutura, agência e interpretação são mais apropriadamente tratadas quando definidas como elementos fundamentais da institucionalização como processo recorrente, garantido e condicionado, não determinado, por certo grau de estabilização dos sistemas sociais. Concluímos o ensaio com considerações metodológicas sobre as consequiências do uso da proposta de abordagem sistêmico-processual recorrente da institucionalização para o desenvolvimento de pesquisas no campo dos estudos organizacionais.

Palavras-chave: teoria institucional; institucionalização; estrutura social; agência; esquemas interpretativos.

\begin{abstract}
The neoinstitutional theory has been characterized by some scholars in the field of organizational studies as a supposedly deterministic approach. We will demonstrate in this paper that this characterization cannot be impinged on the neoinstitutional perspective in a generalized way, but only to a dichotomic reading of it, that is typical of monoparadigmatic views of the process of institutionalization. With this demonstration, we defend the idea of the institutional theory as a multiparadigmatic theory. To this end, we present arguments for a recursive approach of the institutionalization process, highlighting that the notions of structure, agency and interpretation are more suitably dealt with when defended as fundamental elements of institutionalization as a recurrent, guaranteed process that is conditioned, not determined, by a certain degree of stabilization of social systems. We conclude the essay with methodological considerations on the consequences of the use of the proposal for a recurrent systemic-process approach of institutionalization for the development of research in the field of organizational studies.
\end{abstract}

Key words: institutional theory; institutionalization; social structure; agency; interpretive schemes. 


\section{INTRODUÇÃO}

A despeito das costumeiras referências às obras de Philip Selznick publicadas nas décadas de 40 e 50 do século vinte, as origens da teoria institucional remontam ao século dezenove, como demonstra Scott (2001) por meio de síntese esclarecedora da emergência e do desenvolvimento dessa abordagem nas ciências sociais - notadamente na ciência política, na economia e na sociologia. No entanto, a popularidade da teoria institucional é fenômeno relativamente recente no meio acadêmico, circunscrito em especial às últimas décadas.

No campo dos estudos organizacionais especificamente, é notável a adesão crescente de pesquisadores à perspectiva institucional de análise, tanto no exterior como no Brasil. Esta popularidade está provavelmente relacionada à simples constatação de que poucas teorias vêm sendo tão frutíferas no domínio dos estudos organizacionais, nos últimos anos, como a teoria institucional. Talvez isto se deva ao fato de que tal abordagem esteve sujeita, durante grande parte deste tempo, a crítica intensa, nem sempre proveniente de estudiosos de outras perspectivas teóricas, mas, principalmente, de adeptos da própria teoria institucional ou, pelo menos, daqueles que exploram a sua interface com outras vertentes de análise das organizações (vide, por exemplo, DiMaggio \& Powell, 1991; Oliver, 1991; Selznick, 1996; Tolbert \& Zucker, 1996).

Tal crítica, em geral, é conduzida com base em articulações conceituais, que passam pela identificação de supostas decorrências do processo de institucionalização e culminam na sugestão de certa tendência determinista subjacente a uma versão específica da teoria institucional, à qual posteriormente se convencionou designar de neo-institucionalismo. Até mesmo no momento em que a teoria neo-institucional adquire vigor no campo dos estudos organizacionais, esta orientação crítica aparece nos moldes apontados.

No Brasil, esta suposta tendência determinista foi recentemente interpretada por Carvalho, Goulart e Vieira (2004) como conservadorismo moral. Porém, ao tratarem como equivalentes os conceitos de determinismo e de conservadorismo, esses autores retiram o debate do campo propriamente científico e o remetem ao plano moral do juízo de valor. Ao procederem assim, eles ignoram o conjunto de valores sustentadores da prática científica, que constituem o critério pelo qual uma teoria deva ser avaliada como racionalmente aceitável, para se posicionarem no terreno movediço e contraditório dos valores morais. Valores praxiológicos relacionados à natureza da ciência, nas diversas acepções e possibilidades, são 
importantes no contexto de avaliação da atividade científica. É preciso separá-los, analiticamente, de valores morais, para se alcançar coerência intersubjetiva sobre os fundamentos dos juízos científicos que levam à aceitação ou à rejeição de formulações teóricas.

A separação analítica entre esses tipos de valores relaciona-se à noção de legitimidade da prática científica, circunscrevendo a avaliação de teorias às bases ontológicas e epistemológicas que lhes proporcionam suporte. Deste modo, se evita a redução simplificadora ao conceito de neutralidade, clara impossibilidade nas ciências sociais, e se remete o debate ao plano do entendimento de critérios aceitáveis, de um ponto de vista necessariamente racional, ainda que limitado e em processo permanente de aperfeiçoamento, para avaliação, desenvolvimento e escolha de teorias.

Sob esse prisma, Lacey (1998) discorre a respeito das possibilidades analíticas do conceito de imparcialidade, em contraposição aos conceitos de neutralidade e autonomia, para a verificação de teorias. A imparcialidade, como valor de referência da ciência, no entendimento desse autor, precisa ser um ideal a ser buscado, uma vez que a neutralidade e a autonomia constituem impossibilidades em razão do envolvimento do pesquisador e da diversidade complexa e contraditória dos valores sociais. Como ideal científico, a imparcialidade referese especificamente às razões epistêmicas para aceitar ou rejeitar teorias, significando que "as relações que uma teoria mantém com qualquer perspectiva de valor são irrelevantes para a sua legítima aceitação" (Lacey, 1998, p. 14). O conceito de imparcialidade relaciona-se ao necessário exercício de distanciamento analítico por parte do pesquisador, que não consegue ser neutro ou autônomo, mas procura manter coerência com os pressupostos epistemológicos e ontológicos referentes à noção de ciência e de sociedade subjacentes à perspectiva teórica que adota para análise do mundo social.

Cabe acrescentar ainda que a equivalência atribuída aos conceitos de determinismo e de conservadorismo moral por Carvalho et al. (2004) parece repousar em visão maniqueísta de mundo, da qual decorre a postura prescritiva que permeia o trabalho referido. Em decorrência, a perspectiva institucional de análise é por eles reduzida a uma simples abordagem de fundamento dicotômico, na qual persistência e mudança se opõem: persistência é, por definição, atributo negativo, porque necessariamente conservadora; mudança é, também por definição, atributo positivo, porque necessariamente reformadora. Note-se que a equivalência dos conceitos de determinismo e de persistência ao epíteto conservadorismo, se for efetivamente levada em consideração, retira a possibilidade de tratá-los como conceitos descritivos, cientificamente úteis no âmbito da teoria institucional. 
Argumentamos que o dualismo entre persistência e mudança conduz à distorção de noções e conceitos relevantes para melhor compreensão e para o próprio desenvolvimento da teoria institucional. Tais noções e conceitos, visualizados com base em uma perspectiva sistêmico-processual de dualidade ao invés de dualismo entre persistência e mudança, de recorrência processual entre homogeneidade e heterogeneidade, de recursividade entre estrutura e agência, são essenciais para o pleno entendimento da teoria institucional à luz da ontologia e da epistemologia que sustentam a definição dos seus pressupostos e para a sua adequada utilização nos estudos organizacionais.

Do ponto de vista ontológico, a posição que adotamos aqui não é objetivista e tampouco subjetivista, no senso estrito destes termos; é, decididamente, intersubjetiva. Entendemos que o conceito de intersubjetividade é mais apropriado como pressuposto de uma abordagem recursiva do processo de institucionalização. A noção de intersubjetividade possibilita o estabelecimento de pontes significativas em relação aos conceitos de subjetivo e objetivo, uma vez que se refere ao compartilhamento de significados atribuídos por atores individuais em cada situação social específica, garantindo uma objetividade localizada, porque espaciotemporalmente delimitada. Os desdobramentos epistemológicos, teóricos e metodológicos de tal pressuposto são explorados na seqüência deste ensaio.

Em face do exposto, o objetivo do presente ensaio é apresentar para reflexão daqueles que se dedicam a conhecer e a aprimorar a teoria institucional elementos para a adoção de uma abordagem recursiva do processo de institucionalização, em contraposição ao emprego de qualquer visão dicotômica que imponha limites à progressão da perspectiva institucional de análise. Pretendemos demonstrar que estrutura, agência e interpretação são mais apropriadamente tratadas quando definidas como elementos fundamentais da institucionalização como processo recorrente (institutionalizing), garantido e condicionado, não determinado, por certo grau de estabilização dos sistemas sociais.

Em conformidade com esta linha de argumentação, cabe aos atores sociais, mediante sua capacidade de agência, a participação no processo de construção social da realidade, a partir de condicionantes estruturais que não apenas constrangem, mas também possibilitam a ação social, na medida em que são criados pelos próprios atores sociais por meio do compartilhamento intersubjetivo de interpretações. Coerente com esta posição, a orientação adotada é aquela do intelectual específico, em oposição à postura autoritário-moral do intelectual universal, nos termos definidos por Foucault (1979). Uma análise interessante a propósito desta distinção de Foucault encontra-se em Adorno (2004).

Assim, com a finalidade de desdobrar e aprofundar os argumentos precedentes, o presente ensaio está dividido nas seguintes seções: a teoria institucional e seus 
críticos; a teoria institucional como teoria multiparadigmática; estrutura, agência e o primado da interpretação: institucionalização como processo recursivo; e, por fim, a conclusão.

\section{A Teoria Institucional e seus Críticos}

Zucker (1991) inicia sua discussão a respeito da diferenciação entre institucionalização e persistência cultural com a indicação da permanência de características sociais como definição comumente aceita para o conceito de instituição. Para a autora, as explicações tradicionais para a persistência de características culturais a vinculam com o fenômeno institucional. Conforme a vertente sistêmica, os padrões institucionais ou culturais persistem porque preenchem necessidades funcionais. Na vertente normativa, eles persistem porque se fixam, ou são internalizados, enquanto normas compartilhadas de ação. Segundo ela, em ambas as vertentes "o ator não possui um papel independente na manutenção das instituições; [padrões culturais] servem para pressionar o seu comportamento. A estrutura social (nível macro) determina o comportamento de indivíduos e pequenos grupos (nível micro) e existe independentemente deles" (Zucker, 1991, p. 84).

Nestes termos, Zucker (1987, 1991) inclui o desenvolvimento da teoria institucional realizado até então no âmbito paradigmático da teoria funcionalista e propõe uma abordagem interpretativa (etnometodológica e fenomenológica) dela. Com isso, distingue a persistência cultural como decorrência e não mais como característica do processo de institucionalização, sugerindo que o grau de institucionalização se eleva na medida do aumento da transmissão, da manutenção e da resistência à alteração dos padrões culturais compartilhados.

As conseqüências conceituais deste privilégio dado pela autora à dimensão cognitiva do fenômeno institucional, bem como o seu foco monoparadigmático no que concerne à cognição e às instituições, foram generalizados para todos os princípios da teoria institucional, demarcando as críticas vindouras. Portanto, apesar da mudança paradigmática explícita na proposta de Zucker $(1987,1991)$ e de suas implicações, entre as quais se consideram as mais relevantes a substituição da ênfase nos aspectos normativos para os aspectos cognitivos, da abordagem estrutural para a abordagem processual, e o resgate do ator, tanto individual como organizacional, enquanto agente essencial no processo, a institucionalização continua sendo identificada, em essência, com permanência, homogeneidade e conformidade. A normalização ainda é vislumbrada como característica fundamental de tal processo, a partir do emprego de argumentos 
de autores como Selznick (1992, p. 232, grifo do autor), ao afirmar que "enquanto idéia abstrata, despojada de conotações normativas, institucionalização é a emergência de padrões ordenadores, estáveis, socialmente integradores, de um contexto de atividades instáveis, frouxamente organizadas, ou estreitamente técnicas". Note-se, neste sentido, que no estágio mais avançado de institucionalização, o nível de variação na adoção de um padrão cultural é descrito por Tolbert e Zucker (1996) como sendo baixo, mesmo em se tratando de atores sociais com características heterogêneas.

Acreditamos que a insistência em tal conotação também advém do freqüente destaque dado a certos argumentos de DiMaggio e Powell $(1983,1991)$, que, em sua tentativa de distinguir tipos de isomorfismo e, posteriormente, marcos da teoria institucional, estabeleceram a divisão entre isomorfismo coercitivo, mimético e normativo, bem como entre o que denominam velho e novo institucionalismo, acabando por instaurar modelos ainda hoje praticados, de maneira excessivamente segmentada e estanque (vide Mizruchi \& Fein, 1999). No que tange à dinâmica organizacional os autores associam o velho institucionalismo com mudança e o novo institucionalismo com permanência. O pouco que se discutiu até aqui já revela indícios para se negar a dicotomia impressa a esta distinção didática de DiMaggio e Powell $(1983,1991)$ por parte de alguns estudiosos. De fato, afirmamos que esta dicotomia não pode ser aceita, uma vez que, ao contrário do que se apregoa, a persistência de padrões sociais não está ausente dos pressupostos do velho institucionalismo e tampouco o ator social é desconsiderado, como conseqüência, no novo institucionalismo. No entanto, parece encontrar-se subjacente a tal esforço de distinção, dada tendência valorativa que não se explicita claramente, porém que emerge do elenco de pontos utilizado pelos autores para caracterizar as duas supostas fases da teoria institucional, e que persevera na crítica atual à teoria neo-institucional, servindo de suporte à crítica brasileira, em particular.

No que se refere à veiculação de desconsideração do ator social na teoria neoinstitucional, Oliver (1991), por exemplo, procura esclarecer este equívoco, ao propor uma tipologia das diferentes reações estratégicas de organizações às pressões ambientais, construída com base na conjugação das perspectivas institucional e de dependência de recursos. Ela justifica a necessidade de elaboração de tal conciliação teórica, ao detectar a crítica crescente à falta de atenção ao comportamento auto-interessado e à agência ativa das organizações em resposta ao ambiente, no âmbito de parte dos estudos fundamentados na teoria institucional. A autora sintetiza os aspectos da teoria institucional que refletem tal situação, os quais ela utiliza para formular as hipóteses do seu estudo. São eles: "ambiente institucional; comportamento de não-escolha; conformidade a normas e crenças coletivas; pressões invisíveis; isomorfismo; aderência a regras 
e normas; persistência organizacional; hábito e convenção; significação social; conformidade a critérios externos; interesses institucionalmente definidos; autoconsentimento" (Oliver, 1991, p. 147).

Na realidade, a síntese empreendida por Oliver (1991) expõe os pontos principais que, atribuídos à teoria institucional, ou, mais comumente, ao novo institucionalismo, constituem alvo de críticas: a oposição teórica entre padrões institucionais e capacidade de agência (a não-escolha como foco da teoria institucional); a conformidade como tendência comportamental resultante do processo de institucionalização; a persistência (não-mudança) como produto do processo de institucionalização.

Em face disso, Oliver (1991) sugere que as organizações respondem de modo diferente ao ambiente mediante a formulação de ações estratégicas, que variam desde a conformidade até a resistência, de acordo com as pressões contextuais que pendem sobre elas, além da sua capacidade interna e dos motivos que geram tais pressões, de quem as exercem, do tipo de pressões, de como, por quais meios e onde são exercidas. Portanto, a conformidade às exigências ambientais não é inevitável. Entretanto, por não fornecer informações mais detalhadas a respeito da maneira como tal variação pode se dar, inferimos que a autora supõe ser relevante o uso das duas abordagens teóricas, que fundamentam o seu estudo, como mecanismos para a revisão de respostas organizacionais possíveis, o que ela o faz sem, contudo, rever os pressupostos delas. Talvez o único ponto de revisão da teoria institucional presente no seu trabalho seja a idéia de condições institucionais, cuja definição permite presumir que a legitimidade, quando considerada um padrão objetivo e externo, pode ser intencionalmente buscada e, assim, padrões institucionais podem ser alvo de aceitação ou de rejeição pelas organizações.

Apesar de não advir da mera sobreposição de teorias, a noção de condições institucionais não parece ser suficiente para suprir aquelas limitações identificadas na teoria neo-institucional. Pelo contrário, pode até mesmo mantê-las. Como Tolbert e Zucker (1996) observaram posteriormente, Oliver (1991) conclui na sua investigação que, dependendo do grau de institucionalização, haverá maior ou menor margem para resistência e mudança. Nestes termos, instituição continua a ser considerada como sinônimo de conformidade, persistência e não-ação. Todavia, mesmo sob o peso de uma leitura parcial e, por conseguinte, do seu consentimento, ainda que implícito, a argumentação crítica de Oliver (1991) e de outros autores, tais como DiMaggio (1988) e Aldrich e Fiol (1994), impulsiona o realce de elementos já existentes, mas pouco desenvolvidos na teoria neoinstitucional, referentes à capacidade de agência e à sua relação necessária com o fenômeno institucional. 
Não obstante, apesar de algumas tentativas de contrapor aspectos da distinção empreendida por DiMaggio e Powell (1991), no contexto brasileiro a teoria neoinstitucional continua a ser entendida por alguns autores a partir de estrita e estreita visão dicotômica, sendo vislumbrada, assim, como perspectiva que privilegia a estabilidade, a persistência ou a permanência, e a suposição de instituições tão somente como limitadores da ação organizacional.

Embora questione a oposição entre o velho e o novo institucionalismo, em texto recente Misoczky (2003, p. 158), por exemplo, afirma que o novo institucionalismo

Sugere que as preferências individuais e categorias básicas do pensamento, como self, ação social, Estado e cidadania, são moldadas por forças institucionais, enfatiza os modos como a ação é estruturada e a ordem tornada possível através de sistemas de regras compartilhadas, que ... limitam a inclinação e capacidade dos atores para otimizar.

Permanece a associação dos pressupostos da teoria neo-institucional com a noção de ação estruturada, entendida como uma versão renovada da não-ação; em consequiência, a idéia de considerá-los como propulsores de determinismo ambiental, na medida em que são vistos como opostos à lógica da ação estratégica predominante na primeira fase do institucionalismo.

Destaca-se, ainda, na crítica brasileira, a ênfase na dimensão do poder como forma de superar certa tendência que, do ponto de vista dos autores citados, se apresenta como conservadora, e marca a teoria neo-institucional em decorrência da substituição do foco analítico inicial do velho institucionalismo na natureza política da relação da organização com o ambiente pelo imperativo da legitimidade como 'determinante' dessa relação, conforme identificado por Selznick (1996). O poder é então concebido como fundamentalmente vinculado à intencionalidade, enquanto condição necessária para que se resgate a lógica da mudança e da diversidade na teoria institucional. Nas palavras de Carvalho et al. (2004, pp. 11-12):

O caráter específico e a competência distinta, categorias centrais na análise de Selznick ..., enfatizam diversidade e mudança organizacionais; já a legitimidade e o isomorfismo, bases das formulações de Meyer e Rowan ... destacam a homogeneidade e a persistência de formas organizacionais. Aí também se revela a natureza política do velho institucionalismo por meio da centralidade do poder no processo de institucionalização e a neutralidade do mesmo processo na nova versão .... A conformação substitui a mudança e a reprodução assume o lugar da transformação. A homogeneidade sobrepõe-se à heterogeneidade, o global ao local, a adaptação à diversidade. 
Porém, autores como Perrow (1986) afirmam que a principal contribuição da teoria neo-institucional para os estudos organizacionais é salientar a influência do ambiente, ao inserir a legitimidade e o isomorfismo como fatores vitais para a sobrevivência das organizações. Assim, tais diferenças, ao invés de uma marca, resultam tão somente da adoção de outros princípios ontológicos e epistemológicos pela teoria neo-institucional, conforme observa Scott (2001), o que é característico da progressão científica. Além disso, como argumentam Hrebiniak e Joyce (1985), no campo dos estudos organizacionais, boa parte das pesquisas trata extremos de um continuum como se fossem, simplesmente, categorias mutuamente exclusivas. Eis o perigo da dicotomização, como adverte Whittington (1988): focalizar um extremo, sob pena de obscurecer a compreensão e a aplicação do outro.

Contemplando esse aspecto, entendemos que a solução proposta por alguns estudiosos brasileiros para reverter o suposto conservadorismo [determinismo] da teoria neo-institucional, qual seja, o retorno à ênfase no poder, invariavelmente fundamentado na perspectiva única da intencionalidade, se torna próxima do pressuposto racionalista; pelo menos no que toca à sua subjacente orientação voluntarista. À negação do papel primordial da legitimidade e da interpretação, acrescenta-se, ainda, a omissão da noção de reciprocidade como outra base reveladora da conexão entre organização e ambiente, mais bem traduzida pela concepção de imbricação social (embeddedness), definida por Granovetter (1985) e acolhida por proponentes da teoria neo-institucional, tais como Fligstein (1985), DiMaggio e Powell (1991) e outros.

Nessa linha de análise, não custa relembrar que a teoria neo-institucional se situa mais apropriadamente em posição intermediária no continuum entre as orientações determinista e voluntarista da ação organizacional. Tal posicionamento expressa a compreensão de que ela é formulada de acordo com a reciprocidade entre exigências internas e externas, a partir de escolhas guiadas pela interpretação intersubjetiva dos atores sociais sobre a racionalidade predominante no próprio contexto social (Fonseca \& Machado-da-Silva, 2002; Machado-daSilva \& Fonseca, 1993; Machado-da-Silva, Fonseca, \& Fernandes, 2000). Nesse caso, uma racionalidade limitada, nos moldes definidos por Simon (1979).

O que se observa também pode ser descrito como o antigo receio da concepção supersocializada de ser humano, que se vincula ao funcionalismo tradicional, tendo o seu contraponto na concepção subsocializada, típica do racionalismo (Granovetter, 1985). Contudo, tais categorias não representam o que parece estar contido, mesmo que por vezes em termos ainda embrionários, na teoria neo-institucional e em parte da produção acadêmica designada como neoinstitucionalista. Apesar das posições monoparadigmáticas expostas até aqui, 
entre as quais a que prescreve o poder como elemento analítico central da relação da organização com o ambiente, a teoria neo-institucional parece ser mais bem apreendida, quando é vislumbrada enquanto esforço para superar certas barreiras paradigmáticas das ciências sociais. Essa é a idéia que se desenvolve na seqüência do presente ensaio, além da apresentação de outra vertente de explicação da agência e de sua associação com o poder, a mudança e a heterogeneidade organizacional, numa inversão do argumento predominante na crítica brasileira.

\section{A Teoria Institucional como Teoria Multiparadigmática}

Sob a influência da visão esquemática proposta por Burrell e Morgan (1979), boa parte dos adeptos da teoria das organizações parece encontrar dificuldades para pensar além das fronteiras paradigmáticas rigidamente estabelecidas por eles, com objetivos claramente didáticos como eles adequadamente observam. Deste modo, mesmo em face de perspectivas teóricas de difícil enquadramento, no que se refere aos seus fundamentos ontológicos e epistemológicos, alguns pesquisadores tendem a evidenciar certos aspectos conceituais, a desconsiderar outros e a formular classificações mais convenientes às suas próprias intenções, quando talvez o reconhecimento da impossibilidade de ajuste nos tipos convencionais devesse ser a atitude mais coerente. Isso parece se aplicar aos princípios da teoria neo-institucional.

DiMaggio e Powell (1991, p. 8) afirmam que nos estudos organizacionais e na sociologia, a teoria neo-institucional é caracterizada por quatro elementos principais:

Uma rejeição aos modelos de ator-racional, um interesse em instituições como variáveis independentes, um movimento em direção a explicações cognitivas e culturais, e um interesse em propriedades de unidades de análise supraindividuais que não podem ser reduzidas a conjuntos ou a conseqüências diretas de atributos ou motivos individuais.

Conforme observamos anteriormente, tais elementos delimitam a crítica à teoria neo-institucional. Embora não se possa negar a sua existência enquanto pontos relevantes do novo institucionalismo, pretendemos evidenciar que esses elementos referem-se a uma versão específica da teoria neo-institucional em organizações, sem, contudo, esgotar todas as suas possibilidades.

No que concerne à rejeição dos modelos baseados no pressuposto de atores racionais, convencionou-se considerar a teoria neo-institucional como abordagem determinista e os processos de institucionalização como relacionados à não-ação. 
De fato, Tolbert e Zucker (1996) contrapõem o que chamam de modelo de ator racional ao modelo institucional, propondo a superação da dicotomia institucional versus racional. Note-se que, após registrar essa dicotomia, as autoras identificam um modelo de ator social (portanto institucional), associado com indivíduos demasiadamente socializados, que aceitam e seguem normas sociais sem qualquer questionamento, reflexão ou resistência, a partir de seus interesses pessoais.

Tal conseqüência dos processos de institucionalização reflete interpretação equivocada da obra de Berger e Luckmann (1967, p. 55), fundamento de base fenomenológica de vários estudos institucionalistas, quando eles revelam que "as instituições, também pelo simples fato de existirem, controlam a conduta humana estabelecendo padrões previamente definidos de conduta, que a canalizam em uma direção por oposição às muitas outras direções que seriam teoricamente possíveis". Dada essa expectativa determinista da ação, que não se encontra na concepção geral de construção social da realidade desses autores, Tolbert e Zucker (1996), por exemplo, criticam a idéia presente no artigo de Meyer e Rowan (1977) acerca da possibilidade de desconexão entre estruturas formais institucionalizadas e operação técnica de organizações. Elas argumentam que do ponto de vista da lógica expressa por Berger e Luckmann (1967), elevados graus de institucionalização não dariam margem a diferentes respostas organizacionais, e sim o inverso. Entre outros aspectos a serem ressaltados neste ensaio em momento oportuno, apesar da sua validade parcial, sustentamos que a crítica não reflete a multiplicidade paradigmática existente na idéia de Meyer e Rowan (1977) e tampouco a lógica relacional presente na visão de Berger e Luckmann (1967).

Para além do argumento fenomenológico, Hasselbladh e Kallinikos (2000) distinguem uma abordagem que definem como funcionalismo simbólico. Tal definição subentende a possibilidade de ocorrência de diversos níveis ou esferas sociais de produção de padrões institucionalizados e do seu uso estratégico em certas ordens, para que se obtenha legitimidade, mesmo que no contexto local imediato de atuação da organização seja baixo o grau de institucionalização desses padrões. Além disso, implica conceituação diferente de instituição, mais abrangente do que apenas compartilhamento de significados ou de tipificações sociais. Nos termos de Selznick (1996, p. 273), envolve reconhecer que "a estrutura formal é institucionalizada tanto de dentro como de fora" da organização, e que esses dois fluxos, se vislumbrados como momentos distintos e não simultâneos, podem não coincidir, seja nas suas dimensões aparentes ou operacionais, seja no seu significado.

Portanto, a idéia de Meyer e Rowan (1977) consiste em um exemplo do que vem sendo crescentemente designado de padrões institucionalizados ou 
estruturados de cognição (Cochia \& Machado-da-Silva, 2004; Machado-da-Silva \& Barbosa, 2002; Selznick, 1996) e de como esse conceito permite discutir poder da perspectiva cognitiva e cultural, focando, então, os interesses, ao contrário do que se presume em investigações de cunho monoparadigmático. Como admite Selznick (1996), esse aspecto da teoria neo-institucionalista não condiz com a suposição de que ela sustenta a supressão da capacidade racional e que, assim, seja determinista. De acordo com as suas palavras, os "novos teóricos acertadamente dão grande peso à 'cognição estruturada'. Essa idéia bastante útil nos lembra que a interação da cultura com a organização é mediada por uma mente socialmente construída, isto é, por padrões de percepção e avaliação" (Selznick, 1996, p. 274). Tal argumento expressa uma natureza funcionalista, condensada no que ele conceitua como institucionalização localizada (thick institutionalization) ao observar que os "sistemas formais agem somente por meio de pessoas. Uma realidade social deve ser criada, e esta realidade, que tem dinâmica e imperativos próprios, empresta textura para a organização" (Selznick, 1996, p. 235). Sob esta ótica, se mescla funcionalismo com uma abordagem construtivista e interpretativista, o que não parece haver sido captado por Tolbert e Zucker (1996) e tampouco pelos já citados críticos brasileiros.

Logo o que Selznick (1996) identifica no novo institucionalismo não é a negação da racionalidade do agente e, em consequiência, da capacidade de agência, mas a inclusão nos estudos organizacionais da idéia de racionalidade limitada, como princípio de tomada de decisão e de interação, conforme pregam também Roberts e Greenwood (1997), Machado-da-Silva et al. (2000), Fonseca e Machado-daSilva (2002), Crubellate, Grave e Mendes (2004), entre outros. Em concordância com Beckert (1999), entendemos que a teoria neo-institucional contribui para substituir a noção de atores dominados culturalmente ou de atores racionais impossibilitados de seguir o seu curso instrumental de decisão por exigências de práticas institucionalizadas em um campo organizacional.

Há uma segunda versão que parece não rejeitar, mas se tornar mais receptiva àqueles modelos pela aceitação da idéia de que a mente dos agentes organizacionais é socialmente (cognitiva e culturalmente) constituída (Granovetter, 1985; Selznick, 1996). Então a sua ação, mesmo que intencionalmente racional, permanece limitada por padrões institucionalizados. Essa noção de limites da racionalidade, na sua vertente original ou na sua aplicação institucional, repousa sobre abordagem multiparadigmática de teoria social, uma vez que se assenta, pelo menos, sobre pressupostos estruturais e interpretativistas.

Na seção seguinte deste ensaio discutiremos versão complementar dessa noção de limitação da racionalidade, defendendo que, numa perspectiva institucional de análise, parece plausível supor que, embora padrões institucionais limitem a 
possibilidade de ação racional, são os mesmos padrões que, concomitantemente, possibilitam alguma ação e, assim, alguma racionalidade. $\mathrm{O}$ argumento central a ser desenvolvido é o de que, mediante referências institucionais, se encontram ações racionalmente limitadas. Na ausência de instituições, o que se pode encontrar é ação que não pode ser propriamente classificada como social, portanto uma forma de 'não-ação' do ponto de vista da vida humana associada.

Nessa discussão insere-se ainda a noção de que predomina na teoria institucional uma visão das instituições enquanto variáveis independentes. Dado que "atores e seus interesses são institucionalmente construídos" (DiMaggio \& Powell, 1991, p. 28), restaria explorar tal direção de determinação. O enfrentamento a essa suposta tendência em geral ocorre por meio da tentativa de focalizar o processo de institucionalização, como o fazem Zucker (1991), Tolbert e Zucker (1996), entre outros. Entretanto os esforços para enfatizar o processo de institucionalização freqüentemente não contemplam uma discussão da mudança, da capacidade de agência, do poder e dos interesses como elementos constitutivos do próprio processo. Na maioria das tentativas, tais elementos continuam a ser definidos como externos e apenas concomitantes ao fenômeno das instituições e ao processo de institucionalização, gerando perspectiva mecanicista e estática de mudança social, uma vez que opera dentro de um quadro de referência monoparadigmático.

Tolbert e Zucker (1996), por exemplo, encaram o processo de institucionalização como unidirecional, seguindo uma lógica de habitualização, objetivação e sedimentação. Sob esse ângulo, a aparente reconciliação entre estruturas institucionais e agência é realizada mais pela junção e acomodação de teorias do que pela reformulação e avanço da teoria institucional. É a acomodação de teorias que permitiu, nos termos de Seo e Creed (2002), encaminhar os paradoxos da contraposição entre instituição e agência, e da possibilidade de mudança institucional, sem destacar o papel ativo e a imersão social (embeddedness) de agência e interesses. Estes autores constataram tal paradoxo a partir do uso de perspectiva dialética da teoria institucional, o que não foi apreendido ou não é reconhecido por alguns críticos brasileiros do novo institucionalismo, que insistem na versão mecanicista da inserção da categoria do poder como suficiente para reverter a visão das instituições como variáveis independentes. Outras versões dessa suposta reconciliação entre instituições e mudança geralmente apenas invertem a lógica da relação, e assim instituições deixam de ser vistas como variáveis independentes, a causa dos interesses e das ações, para se tornarem variáveis dependentes, produto das intenções de agentes poderosos e conscientes de seus interesses, ou consideram as contradições institucionais a fonte de suas mudanças. Tais tentativas refletem o que DiMaggio e Powell (1991, p. 30) definem como "fontes extra-institucionais de mudança institucional". 
De qualquer modo, acreditamos que um avanço no desenvolvimento dos pressupostos da teoria neo-institucional requer explicar a mudança como parte do processo de institucionalização e não como fenômeno correlacionado e externo. Há que se reformular a articulação entre os componentes da teoria, de maneira que instituições e mudança deixem de ser vistas como contraditórias, possibilitando identificar, à semelhança do que propõem Seo e Creed (2002), Dacin, Goodstein e Scott (2002) e outros estudiosos, fontes institucionais de mudança institucional ao longo do tempo.

Essa possibilidade de tratamento da mudança na teoria neo-institucional, ao contrário do que parecem supor DiMaggio e Powell (1991) e que constitui o argumento central do texto de Carvalho et al. (2004), não vem ocorrendo a despeito do seu foco cognitivo-cultural, mas sobretudo em razão dele. A origem dessa abordagem se encontra na proposta de Ranson, Hinings e Greenwood (1980). Partidários da sociologia da estruturação de Giddens (1978), eles compreendem a estrutura como mutuamente constitutiva da ação e por ela constituída, enquanto fruto de um arcabouço prescrito de regras e de procedimentos e de padrões emergentes de interação, resultantes da contínua interpretação deles na rotina da organização. Evidencia-se aí a idéia de reciprocidade, para além da limitação analítica do quarto ponto destacado por DiMaggio e Powell (1991) como característico da teoria neo-institucional, qual seja, a análise de estruturas supra-individuais.

Scott $(1994,1995)$ tampouco parece vislumbrar a teoria neo-institucional a partir da distinção de variáveis ou de estruturas supra-individuais. Ao propor uma síntese teórica, ele inclui as noções de ator social e de interpretação como elementos importantes no processo de institucionalização. Tal circularidade também pode ser captada como reciprocidade, caso se destaque o conceito de ação social que fundamenta a sua abordagem. Nas suas palavras,

seguindo Weber ... ação é vista como social somente na extensão em que atores atribuem significado a ela. Os estímulos ambientais devem ser cognitivamente processados pelos atores - interpretados por indivíduos empregando sistemas de símbolos socialmente construídos - antes que eles possam responder adotando uma ação (Scott, 1995, p. xiii).

Se Ranson et al. (1980) se baseiam na sociologia da estruturação, Scott (1994, 1995) implicitamente se apóia na sociologia neofuncionalista. Nesse sentido, tais autores representam uma versão do novo institucionalismo que não se restringe às características propostas por DiMaggio e Powell (1991), uma vez que tratam, embora de modo embrionário, o processo de institucionalização numa perspectiva multiparadigmática e orgânica, fundamentada em lógica cognitivo-interpretativa. Desconsiderar essa versão se justifica apenas pela parcialidade da sua leitura ou 
pelo viés politicamente engajado da sua interpretação; até mesmo porque é ela que prevaleceu nos principais centros de investigação da teoria neo-institucional, a partir de meados da década de 90 do século vinte, e não a suposta vertente determinista, como observam Seo e Creed (2002) e outros.

Um dos principais elementos teóricos que possibilita a adoção dessa abordagem institucional, como demonstraremos a seguir, é a noção de agência que, discutida em outro âmbito, implica reconhecer que o processo de institucionalização, enquanto fenômeno complexo, não descarta, mas pressupõe tanto a mudança como a persistência, tanto a imersão social como a autonomia, tanto os níveis microssociais (organizações e agentes individuais) como os planos macrossociais.

\section{Estrutura, Agência e o Primado da Interpretação: Institucionalização como Processo Recursivo}

O conceito de agência subjacente à perspectiva mecanicista de mudança social e o propósito manifesto de alguns autores em resgatar a perspectiva política de entendimento do fenômeno institucional são agora questões que recebem maior elucidação. Para tanto, de início cabe relembrar a afirmação de Selznick (1992, p. 238, grifos nossos) de que "agência denota competência, intencionalidade e calculabilidade. Ser um agente é atuar com propósito". De importância similar para a argumentação são também as considerações de Colomy (1998): esse autor concebe a teoria neo-institucional como portadora de uma concepção de ação de ordem prática, em que a natureza rotineira da conduta humana se destaca e contribui para caracterizar os próprios atores e seus interesses como constituídos pelas instituições. Para ele, ao privilegiar a reprodução em detrimento da transformação, a teoria neo-institucional acaba por reduzir agência à representação (enactment), quando, no âmbito da mudança em particular, deveria contemplar as dimensões tipificadoras e inventivas, reprodutivas e reconstrutivas da ação social.

Parece que Colomy (1998) não se dá conta de que a limitação por ele identificada no neo-institucionalismo se repete igualmente na perspectiva racionalista do empreendedorismo institucional, solução à qual ele se filia, tanto como na proposta de resgate conceitual do poder (conforme discutimos há pouco). Ou seja, se os pressupostos da teoria neo-institucional não permitem explicar os processos de reconstrução e mudança institucional (conforme alguns estudiosos alardeiam), as perspectivas voluntaristas tampouco explicam de modo satisfatório os seus aspectos tipificadores e reprodutivos. Esta simples constatação demonstra que tais perspectivas são igualmente incapazes de abranger a circularidade implícitano conceito de ação 
social. É exatamente a necessidade de romper com a dicotomia reprodução versus reconstrução que constitui o esforço realizado pelos seguidores de uma orientação sociológica baseada na idéia de ação prática, tais como Ranson et al. (1980), Giddens, (1984), Hinings e Greenwood (1988), Machado-da-Silva e Fonseca (1993, 1996a).

Apesar da lucidez com que identifica o atual desafio da teoria neo-institucional, Colomy (1998) incorre em erro no concernente ao sentido que atribui aos conceitos de representação (enactment) e agência. Com relação ao primeiro conceito, a sua adequada discussão extrapola o objetivo do presente artigo. Por ora basta dizer que, para se perceber o equívoco de igualá-lo à mera reprodução da realidade, seria necessário agregar a tal discussão a noção de representação também como configuração inventiva, principalmente na perspectiva multiparadigmática de autores como Weick (1969, 1995, 2001) e Tsoukas e Knudsen (2002).

Quanto ao segundo conceito, Colomy (1998) afirma que a noção de agência predominante na teoria institucional se vincula ao paradigma funcionalista tradicional, sobretudo à noção parsoniana de mudança estrutural. Logo ele não parece reconhecer, da mesma forma que alguns autores já citados, a natureza multiparadigmática da teoria institucional, deixando de captar toda a complexidade nela contida ou, pelo menos, o quanto ela permite desenvolver, em especial no campo dos estudos organizacionais.

Giddens (1984), a exemplo de Selznick (1992), também associa agência à intencionalidade. Contudo ele admite que a intenção é aspecto relevante, porém não suficiente para explicar a capacidade de agência. Assim considera que agência não consiste tão somente na intenção que os indivíduos possuem de realizar as coisas, mas na sua habilidade de fazer tais coisas em primeiro lugar, o que implica poder: segundo ele, em dicionário da língua inglesa, o vocábulo agente significa "aquele que exerce poder ou produz um efeito" (Giddens, 1984, p. 9).

Nesses termos, agência é a capacidade de interferir em eventos, não necessariamente de modo intencional. Agir, mais do que pretender algo, é ser significativo na sua ocorrência, na medida em que a "ação depende da capacidade do indivíduo de 'fazer uma diferença' em um estado pré-existente de coisas ou curso de eventos" (Giddens, 1984, p. 14). Tendo em vista essa definição, a intencionalidade do agente não é negada, nem encarada como a característica principal da capacidade de agência. Mesmo que toda ação envolva uma intenção inicial, o seu resultado jamais pode ser explicado completamente por essa intenção, mas apenas quando se reconhece a interferência de consequiências não intencionais. Em determinada ação, quando o indivíduo tenciona um fim $\mathbf{A}$ e alcança um fim $\mathbf{B}$, ele é agente em relação ao fim $\mathbf{B}$, pois participou da sua consecução, embora não intencionalmente. Acrescenta-se a isso a concepção de racionalidade limitada, conforme destacado na seção anterior. 
Mediante essa noção específica de agência, se torna possível, enfim, visualizar a interdependência entre estruturas e ações sociais, sem sucumbir à idéia decausalidade linear entre elas. É nesse sentido que Giddens (1984) entende estruturas como 'traços de memória' que se manifestam, se reproduzem e se reconstroem em qualquer atividade humana prática, em que os atores sociais se expressam como tal. Deste modo, para além de padrões externos e objetivos construídos para exercer pressão sobre a ação, estruturas são referências que permanecem virtuais e latentes até o momento em que alguma prática social ocorre, tornando-se tanto meio como resultado dela. Nos termos de Scott (2001, p. 50), "instituições impõem restrições definindo limites legais, morais, e culturais que separam atividades legítimas de ilegítimas [mas] também sustentam e autorizam atividades e atores. Instituições fornecem guias e recursos para agir bem como proibições e pressões sobre a ação". Portanto a recursividade entre estruturas e ações fundamenta o próprio processo por meio do qual ambos emergem, permeado por configurações contínuas de interpretação.

Todavia, apesar de Giddens (1984) declarar que as instituições são compostas pelas práticas mais longínquas, enquanto fatores duradouros que proporcionam solidez à vida social através da espaciotemporalidade, não se pode depreender da sua afirmação a possibilidade de ocorrência de mera reprodução ou de repetição e permanência rígida de padrões como características do processo de institucionalização, em função da noção de prática, estrutura e agência que ele institui. Acreditamos que os princípios da teoria da estruturação sugerem que, ao invés de serem entendidas como focos de determinação, as instituições devem ser vislumbradas como condição para a manifestação de estruturas sociais e da capacidade de agência; ou de reprodução e recriação das estruturas, ao mesmo tempo que indivíduos se expressam e se constituem como atores sociais. Isso se condição for entendida como ocasião e oportunidade, possuindo concomitantemente sentido positivo e negativo de potencialidade e restrição.

Sob esse prisma, três questões relevantes sobressaem no exame da crítica convencional à teoria neo-institucional. Primeiro, agência e estrutura, "longe de serem opostas, de fato se pressupõem mutuamente", como Sewell (1992, p. 4) observa com propriedade, o que remete à noção de simultaneidade, reciprocidade e imbricação social (embeddedness) entre os dois fenômenos nos moldes explicitados anteriormente. Em segundo lugar, e conforme salientado a partir da argumentação de Giddens (1984), estruturas sociais e, em conseqüência, regras, normas e padrões de cognição, na verdade devem ser considerados tanto como limitadores quanto como habilitadores da ação, nunca como apenas um ou outro. Tal idéia pode ser resumida pelo significado de condição adotado.

Por fim, tem-se que o processo de institucionalização, se considerado o seu estado recursivo tal como defendemos aqui, não pode ser plenamente apreendido sem que a 
interpretação da ação seja evidenciada como o aspecto que possibilita o seu desenvolvimento. Ainterpretação é o mecanismo operacional, de natureza cognitivocultural, da recursividade inerente à institucionalização. É o que desencadeia a reciprocidade entre estrutura e agência, uma vez que ação, seguindo a tradição weberiana, pressupõe processamento de estímulos externos, ou seja, significação. Nessa perspectiva, fixar qualquer direção causal à relação da estrutura com a ação se revela uma posição precipitada, para não dizer ingênua.

No âmbito da teoria neo-institucional, presume-se que o processo de recursividade pode ser assim explicado: qualquer ator social, em qualquer situação diária de resolução de problemas, por exemplo, necessita de referências para agir. Tais referências se apresentam em termos de orientações do passado, ou hábitos, orientações para o presente, ou julgamentos, e orientações para o futuro, ou projeções, de acordo com a definição de Emirbayer e Mische (1998), e são delineadas e consolidadas por instituições como o Estado, a indústria, associações profissionais, entre outras, conforme DiMaggio e Powell (1983). Logo acessar tais referências é interpretar estímulos contemporâneos que sobrevêm no fluxo cotidiano das práticas instauradas por estruturas sociais.

O que urge compreender é que tais referências nunca provêm de modo linear e direto de fonte externa ao agente, mas sempre por meio da interpretação, do significado que ele atribui ao contexto no qual imerge e emerge a prática social. Vale esclarecer que não se nega a presença de uma face objetiva dessas dimensões referenciais; o que se nega é a sua influência direta na ação. Delineado desta forma, o processo de institucionalização se torna eminentemente dinâmico, ao invés de estático; inclui agência, além de estruturas sociais, e acontece tanto em níveis macrossociais como em níveis microssociais. Conseguintemente, é a construção de significados e de interpretações que fornece um caráter dinâmico à institucionalização, não apenas a intencionalidade, pois o agente se concentra somente nos aspectos que percebe como essenciais para solucionar o problema com que se defronta (Fonseca \& Machadoda-Silva, 2002; Machado-da-Silva et al., 2000). Cabe ainda relembrar que o processo de institucionalização implica em questão de grau, na medida em que a fundação e o desenvolvimento de estruturas sociais variam conforme circunstâncias históricas, espaciotemporalmente delimitadas (Machado-da-Silva \& Fonseca, 1996b; Powell, 1991; Scott, 1991).

Em síntese, toda instituição é condição para as estruturas sociais e para a agência. Ela tanto possibilita como limita a constituição e a manifestação da estrutura e da capacidade de agência. Assim não se refere unicamente às estruturas sociais, como também às práticas sociais, que, nas palavras de Giddens (1984), possuem a maior extensão espaciotemporal. A existência de instituições demarca e permite a ação. No entanto, a inexistência delas, se é que se pode pensar nesta possibilidade afora 
em um plano utópico, não representa liberdade irrestrita para a ação social, mas nãoação social, pela ausência de referências.

De acordo com Weber (1924/1998), uma instituição é sempre uma possibilidade de ação. Logo se toda ação é fundamentada em um motivo, do ponto de vista do agente, segundo Cohn (1979); se tal motivo é sempre individual em última instância, conforme afirma Weber (1924/1998); e se instituição diz respeito à ação, ela não pode implicar supressão da capacidade de agência, caso tal capacidade seja limitada apenas à intencionalidade, sob o risco de se incidir em contradição conceitual. Portanto a institucionalização como processo recorrente (institutionalizing), isto é, implicando simultaneidade e reciprocidade entre estrutura e agência, condiciona a ação, na medida em que a delimita e a viabiliza, tornando-a cada vez mais possível, sem, contudo, torná-la necessária e inelutável.

Nessa ótica, não ocorre unicamente reprodução de estruturas, mas a repetição da oportunidade de sua reinterpretação ao longo do tempo; em conseqüência, pode ocorrer reprodução e mudança. Uma prática rígida ou fixa não é uma instituição. É uma 'estrutura morta' em um dado momento, ausente da consciência prática dos atores sociais (Giddens, 1984). Uma prática institucionalizada permanece em estado de equilíbrio provisório e dinâmico: quanto maior for o seu grau de institucionalização, menor a probabilidade de que seja bruscamente modificada. Por outro lado, mesmo uma prática altamente institucionalizada não é imutável no transcorrer do tempo, já que ela sempre estará vindo à tona no contexto das interações sociais, sendo, portanto, submetida à possibilidade de manutenção ou de alteração nos seus aspectos estruturados ou nas ações decorrentes, os seus aspectos estruturantes.

A título de esclarecimento, 'estruturas mortas' diferem de ordens baseadas em costume e hábito. Weber (1924/1998, p. 215) define costume como "um comportamento tipicamente regular que é mantido dentro dos limites tradicionais unicamente por seu caráter de 'habitual' e pela 'imitação irrefletida"'. Sob o foco de análise da abordagem institucional, torna-se então um engano inferir que costume envolva completa homogeneidade e permanência de práticas, pelo menos quando se confere a devida importância à dimensão cognitivo-cultural inerente a toda relação social.

Nesse sentido, ainda que se possa admitir que instituições provocam, em geral, a intenção de aquiescer, sustentamos que tal intenção será afetada pelo fato de que a interpretação implícita no processo de formação das ações, no sentido weberiano, acarretará possíveis desvios do padrão original. É por isso que, mesmo se niveladas com o hábito ou costume, as instituições só podem ser visualizadas como regularidades ou possibilidades, jamais como determinações, em decorrência do aspecto cognitivo-cultural característico de toda e qualquer ação social e não a despeito dele. 


\section{CONCLUSÃo}

A teoria institucional tem despertado bastante atenção no campo dos estudos organizacionais, angariando cada vez mais adeptos, principalmente desde o final da década de 70 do século passado. Se, por um lado, tal popularidade talvez possa ser encarada como produto do seu elevado potencial explicativo, por outro ela parece haver contribuído para o surgimento de críticas intensas, nem sempre orientadas por articulações conceituais consistentes o suficiente para garantir o alcance de adequada compreensão e ampliação dos seus pressupostos. No cerne de tais críticas se encontra a suposta identificação da perspectiva institucional de análise, no âmbito do chamado neo-institucionalismo, com permanência, homogeneidade, conformidade e determinismo, sobretudo quando o foco recai na investigação da mudança organizacional ou do processo de institucionalização. Dancin, Goodstein e Scott (2002, p. 45) já haviam explicitado observação e preocupação semelhantes, ao afirmarem que tal foco crítico "pouco contribuiu para desvelar o verdadeiro potencial da teoria institucional". Em concordância com esses autores, procuramos apresentar neste ensaio elementos que contribuam para a adoção de uma abordagem capaz de gerar análises e investigações mais profícuas para a progressão da teoria neo-institucional.

É possível depreender, do quadro esboçado nas seções precedentes, que a institucionalização é mais bem analisada sob uma ótica multiparadigmática. Nessa perspectiva, estrutura e agência se conectam de modo recursivo, com base na interpretação enquanto mecanismo cognitivo básico, que possibilita a reciprocidade entre tais elementos e, em consequiência, a sua simultaneidade na prática social, além do desenvolvimento do processo ao longo do tempo. Assim os atores se tornam os portadores dos significados institucionais, nos termos definidos por Zilber (2002), ao infundirem ações nas organizações por meio da interpretação de fatores externos e internos, a serem legitimadas mediante compartilhamento e socialização. Estrutura e agência não existem nem se perpetuam por si mesmas, ou a partir da mera influência direta de uma sobre a outra, mas pela interação entre elas promovida pela interpretação de seus componentes, sob condições de legitimidade (Dancin, Goodstein, \& Scott, 2002; Giddens, 1984; Scott, 1995, 2001; Weber, 1924/1998; Zilber, 2002).

À luz desses argumentos, isomorfismo ou homogeneização não expressam necessariamente não-mudança e não-ação, no sentido de ausência de capacidade de agência ou de escolha. Aquiescer a um padrão social pressupõe interpretação e, como tal, implica escolha e ação. Portanto a homogeneização não deriva de reprodução irrefletida, mas de regularidade proveniente da aceitação de determinada ação, que justamente em função de ser interpretada como legítima, é reproduzida pelos agentes na prática social e se consolida como padrão institucionalizado, por ser consentida como escolha desejável e viável. A reprodução gera regularidade, 
não cópia, porquanto, mesmo que a aquiescência seja a intenção, consequiências não intencionais podem acarretar mudanças em decorrência da diversidade de fontes de interpretação e de lógicas de ação que proporcionam significado ao contexto institucional. Não se tem passividade, mas o seu oposto. Não se tem apenas permanência e conformidade, mas variação e mudança (Dancin, Goodstein, \& Scott, 2002; Giddens, 1984; Machado-da-Silva et al., 2000; Ranson et al., 1980; Scott, 1995; Weber, 1924/1998).

Cabe salientar que a legitimidade é garantida por atitude interna ou por expectativa de determinadas consequiências, ao invés de por imposição externa aos agentes, conforme descreve Weber (1924/1998). Deste modo, a interpretação também está vinculada estreitamente com a legitimidade como aspecto fundamental de toda instituição, permitindo compreender porque uma regularidade qualquer de coisas não é considerada instituição: enquanto tal aquela regularidade deve ser explicada pelo fato de os indivíduos submetidos à sua vigência aceitarem a sua legitimidade.

Quando admitimos que a interpretação é crucial na mediação entre fatores externos e ações, torna-se inaceitável ainda a suposição de que o primado da legitimidade na teoria neo-institucional implica diminuição de espaço para agência, interesses, racionalidade, poder e outros elementos representativos da autonomia, em qualquer das instâncias às quais esse conceito possa ser aplicado, seja em nível individual, organizacional ou societário. O que ocorre é o inverso disso. Conforme demonstra Giddens (1984), legitimação enquanto dimensão dos sistemas sociais mantém conexão constante com significação e dominação, que, assim, estão conjuntamente envolvidas em toda a ação. Nestes termos, legitimidade é a palavra-chave da teoria neo-institucional, pois é o elemento que permite a manutenção ou a mudança das instituições: questionamentos a respeito da adequação de práticas, normas e procedimentos em razão de pressões internas e externas podem impossibilitar a reprodução dos padrões institucionalizados, acarretando a perda da sua legitimidade; ou seja, o desencadeamento de um processo de desinstitucionalização, que exige a redefinição e a subseqüiente relegitimação de novos significados e ações, típicas da emergência de um processo de reinstitucionalização (Jepperson, 1991; Machado-da-Silva \& Fonseca, 1996a, 1996b; Oliver, 1992).

Especificamente, alegamos que a simples inclusão mecanicista da categoria do poder como elemento de análise predominante do processo de institucionalização, não permite configurar uma abordagem que contemple a mudança institucional em toda a sua amplitude. Além de se concentrar em estruturas e ações, é necessário identificar o significado atribuído a elas pelos atores sociais e o papel deles no processo desencadeador da mudança, conforme salienta Zilber (2002). Há de se considerar, do ponto de vista da intencionalidade, que atores sociais que já detêm recursos e, 
conseguintemente, poder, são pouco propensos a participar de mudanças que alterem a manutenção da ordem vigente. Assim, a exploração isolada e racionalista do poder acaba dicotomizando a concepção de sociedade, colocando, de um lado, atores influentes em luta constante pela perpetuação da situação em voga e, do outro, atores periféricos que intencionalmente lutam pela mudança para defenderem os seus interesses.

Sob uma perspectiva recursiva que admita a interconexão do poder com outras categorias de análise, esta visão dicotômica se dissolve, tanto quanto se rompe o pretenso dualismo entre permanência e mudança. Ao se vincular poder e legitimidade, se reconhece que o detentor de recursos e de poder os detém porque possui legitimidade. Esta, por sua vez, permite que ele sustente a sua posição e atraia mais recursos ou que conserve os que já detém. Ainda assim, a validade disso se limita ao escopo da intencionalidade dos atores, e não ao que de fato pode vir a ocorrer, pois um recurso é valioso porque é interpretado socialmente como tal, do mesmo modo que a busca por ele e a sua posse são legitimadas no contexto social.

Quando se considera o aspecto interpretativo, compreende-se então que, juntamente com a dominação, a legitimidade constitui o poder. Entende-se, além disso, que é preciso identificar algum grau de sustentação social, nem sempre intencional, mas sempre cognitivo-normativa, que explica o poder de certos atores, o qual se converte, mediante o mecanismo da reciprocidade, em recurso a ser empregado por eles para a manutenção ou a transformação do arranjo estrutural vigente no sistema social. Nele diversos grupos procuram fazer com que os seus valores e interesses predominem e, quando um deles é bem-sucedido, as normas, as regras e os significados compartilhados pelos seus integrantes são legitimados, assegurando-lhes status e autoridade, que eles procuram manter (Ranson et al., 1980). Logo atributos estruturais só se efetivam quando atores sociais os interpretam e se orientam por eles em função dos seus valores e interesses e do significado que lhes atribuem. Até mesmo para que se reconheça uma coerção como tal, é necessário interpretá-la como coerção. Por isso uma instituição é sempre uma possibilidade; qualquer análise que se detenha no nível macrossocial das instituições não permitirá, por conseguinte, distingui-las de 'estruturas mortas'.

Outra consequiência de se enfocar tão somente a natureza política das instituições, em detrimento dos seus aspectos cognitivo-normativos, é tratar mudança como inversão ou revolução, ou seja, como um evento pontual e radical. A tônica de tal visão, ao contrário do que se vem propagando, é a permanência pontuada por revoluções. Na versão da abordagem neo-institucional que apresentamos aqui, admitese que algumas circunstâncias geradoras de intensa ruptura dos padrões institucionalizados podem ocasionar modificações radicais em determinados períodos, 
por envolverem a perda da sua legitimidade. Não obstante, caso se considere o desenvolvimento das instituições ao longo do tempo, verifica-se que grande parte das mudanças tende a ser constante e incremental e, apenas às vezes, fundamental, mas ainda assim compatível com a lógica de legitimação no sistema social, que não pode ser considerado de forma monolítica; sistemas sociais modernos são compostos por diferentes esferas de poder e de representação, entendidas como configurações mais ou menos inventivas, mais ou menos voltadas para a conformidade ou nãoconformidade. "Mudança revolucionária, radical e descontínua é, quase por definição, rara" (Scott, Ruef, Mendel, \& Caronna, 2000, p. 346). Tal constatação permite evidenciar, entre outros fatores, a participação dos detentores do poder no desenvolvimento do processo de mudança, mesmo quando eles procuram manter a ordem estabelecida, e a transformação de organizações e demais atores periféricos em agentes de mudança, mesmo quando o que lhes resta é somente aquiescer. Permite elucidar que não se superam os limites institucionais pela supressão das instituições, senão por causa delas.

As reflexões traçadas no presente ensaio carecem de desdobramentos de natureza metodológica, susceptíveis de conduzir à realização de investigações teóricoempíricas. Inicialmente, sugerimos que já não cabe restringir a análise do processo de institucionalização à identificação do efeito da estrutura social no comportamento social ou, em direção contrária, da definição de ações intencionais, buscando conformar certa ordem institucional favorável aos valores e interesses de atores racionais. É necessário verificar os padrões estruturais vigentes, as ações que eles possibilitam e limitam, quais significados são construídos, modificados e reproduzidos pelos atores para responder às circunstâncias ambientais, o que implica no uso de estratégias de pesquisa capazes de captar a interdependência entre estrutura, interpretação e ação, em diferentes contextos sociais. Nesse sentido, o exame dos esquemas interpretativos se torna essencial para a compreensão da dinâmica organizacional como envolvendo simultaneamente mudança e estabilidade, conforme revelam estudos empreendidos por Bartunek (1984), Hinings e Greenwood (1988), Machado-da-Silva e Fonseca (1993, 1996a), Machado-da-Silva e Gonçalves (2000), entre outros.

Por outro lado, explicar mudanças na estrutura e no comportamento social também requer conceder mais ênfase à análise do processo de desinstitucionalização. A importância do aprofundamento da sua investigação reside na obtenção de esclarecimentos acerca dos fatores motivadores do rompimento da legitimidade de práticas e significados, da intensidade da influência das exigências ambientais na instituição e das condições que desafiam a tendência de adaptação a elas. Apesar de pouco explorado na literatura especializada, Oliver (1992), por exemplo, descreve mecanismos sociais, funcionais e políticos localizados dentro e fora das organizações como fatores fundamentais para a 
ocorrência de processos de desinstitucionalização; Clark e Soulsby (1995) procuraram evidências empíricas do seu desencadeamento no estudo da transição de uma economia centralizada para uma economia de livre mercado na República Tcheca, no final dos anos 80 do século passado; e Zilber (2002) revela como a ideologia feminista predominante em um centro de crise de estupro situado em Israel foi alterada pela disseminação de novos significados a partir da entrada de membros orientados por um foco terapêutico. Aúltima pesquisa é particularmente interessante por ser fundamentada na idéia de que a institucionalização pressupõe o exame da interação existente entre ações, significados e atores, à semelhança do que advogamos no presente ensaio.

Tendo em vista a complexidade dos fenômenos e das relações precedentes, julga-se pertinente empregar também para a sua averiguação empírica, delineamentos que atendam ao requisito da abordagem sistêmico-processual recorrente, conforme proposto neste ensaio. Tais delineamentos devem ser configurados, preferencialmente, em termos de uso de métodos múltiplos, com privilégio para os procedimentos qualitativos de pesquisa, sob uma perspectiva longitudinal e histórica. Esse desenho de pesquisa parece ser o mais apropriado para desvendar a articulação entre referências estruturais, domínios de interpretação e ação, apesar de a completa apreensão da concomitância de manifestação, ajuste recíproco, mudança e manutenção deles ainda persistir como um desafio metodológico a ser superado. No entanto, não se deve descartar o uso de procedimentos quantitativos de pesquisa em combinação com os procedimentos qualitativos, desde que a lógica predominante seja interpretativa e não de causalidade linear. Fotos de uma configuração social, típicas de um corte transversal, podem se constituir em primeiro passo de um processo de pesquisa longitudinal e histórica para desvelar o filme que levou àquela configuração. Obviamente, a recuperação de eventos passados enfrenta limitações que precisam ser adequadamente tratadas na condução do processo de pesquisa.

Não custa ilustrar dois possíveis procedimentos de investigação, entre outros igualmente recomendáveis. O primeiro deles refere-se ao uso da metodologia de análise de redes para verificar a estrutura de relacionamento entre organizações (foto) em combinação com o uso de métodos interpretativos de resgate histórico (filme) do porquê de tal configuração estrutural; a preocupação deve ser a de tentar revelar e entender os elementos estruturadores de tal situação estruturada e estruturante. O segundo concerne ao uso da metodologia de estudo de caso em profundidade para examinar o processo de difusão institucional no âmbito interno de organizações, envolvendo os atores, as estratégias e os mecanismos de atribuição de significados nos diversos níveis e segmentos organizacionais, à luz das diferentes esferas do contexto ambiental. 
Em termos de implicações ontológicas, um passo indispensável para enfrentar tamanho obstáculo é abandonar a posição objetivista, explícita ou subjacente à realização de parte significativa dos estudos organizacionais orientados pela perspectiva institucional de análise, entre os quais se incluem alguns elaborados pelos próprios autores deste ensaio. Recente exemplo de utilização do enfoque objetivista, em voga nos últimos anos entre os adeptos da visão monoparadigmática racionalista da teoria institucional, é aquele que reduz a realidade ao nível do discurso como resultante estruturado tão somente de práticas conscientes de dominação e uso do poder. Tal perspectiva situa-se na contramão da proposta apresentada neste ensaio de abordagem sistêmico-processual recorrente da institucionalização, que implica analisar o discurso organizacional em termos da dualidade de ações comunicativas e propriedades estruturais, recursivamente intermediadas pela interpretação intersubjetiva dos atores envolvidos, à semelhança do entendimento de Heracleous e Hendry (2000).

Por outro lado, é importante ressaltar as possibilidades da abordagem proposta no que concerne ao estudo de decisões estratégicas em organizações, uma vez que elas parecem constituir o contexto onde a recorrência entre capacidade de agência e forças estruturais mais se evidencia. Em decorrência pode-se dar um passo importante na superação da divisão entre o campo de análise das organizações e o campo de estudo da estratégia, que ainda permanecem inexplicavelmente separados nos dias atuais.

Para finalizar este ensaio, corroboramos a idéia de Bowring (2000), quando ele afirma que em algum lugar entre o ponto de origem e os dias atuais, a noção de construção social da realidade passou a ser aplicada com lógica linear causal, visível tanto no conteúdo como na forma até mesmo dos trabalhos seminais de Meyer e Rowan (1977) e DiMaggio e Powell (1983). O conceito básico de intersubjetividade parece ter sido reduzido, ao longo do tempo, primeiramente à subjetividade e, em seguida, à objetividade, desvirtuando a concepção original de Berger e Luckmann (1967), reconhecida como um dos fundamentos da teoria neo-institucional. Talvez essa perda justifique o equívoco em se associar o novo institucionalismo com determinismo e dualismo, que vem caracterizando a análise da relação organização, instituição e ambiente como estática e objetivista; portanto desvinculada da dimensão humana que, justamente, permite situá-la em posição intermediária, nem voluntarista nem determinista, para o entendimento do mundo social e também como abordagem relevante no campo dos estudos organizacionais.

Artigo recebido em 20.10.2004. Aprovado em 20.12.2004. 


\section{ReferênCias Bibliográficas}

Adorno, F. P. (2004).

A tarefa do intelectual: o modelo socrático. In F. Gros (Org.), Foucault: a coragem da verdade (pp. 39-62). São Paulo: Parábola Editorial.

Aldrich, H., \&

Fiol, C. M. (1994).

Fools rush in? The institutional context of industry creation. Academy of Management Review, 19(4), 645670.

Bartunek, J. M. (1984).

Changing interpretive schemes and organizational restructuring: the example of a religious order. Administrative Science Quarterly, 29(3), 355-372.

Beckert, J. (1999).

Agency, entrepreneurs, and institutional change: the role of strategic choice and institutionalized practices in organizations. Organization Studies, 20(5), 777-799.

Berger, P. L., \&

Luckmann, T. (1967).

The social construction of reality: a treatise in the sociology of knowledge. New York: Doubleday Anchor Book.

Bowring, M. A. (2000).

De/constructing theory: a look at the institutional theory that positivism built. Journal of Management Inquiry, 9(3), 258-270.
Burrell, G., \&

Morgan, G. (1979).

Sociological paradigms and organizational analysis. London: Heinemann.

Carvalho, C. A.,

Goulart, S., \&

Vieira, M. M. F. (2004, setembro).

A inflexão conservadora na trajetória histórica da teoria institucional. Anais do Encontro Nacional da Associação Nacional de Pós-Graduação e Pesquisa em Administração, Curitiba, PR, Brasil, 28.

Clark, E., \&

Soulsby, A. (1995).

Transforming former state enterprises in the Czech Republic. Organizations Studies, 16(2), 215-242.

Cochia, C. B. R., \&

Machado-da-Silva, C. L. (2004).

Ambiente, interpretação e estratégia em organizações paranaenses dos setores de vestuário e alimentos. Revista de Administração Contemporânea, 8(Edição Especial), 11-35.

Cohn, G. (1979).

Crítica e resignação: fundamentos da sociologia de Max Weber. São Paulo: T.A. Queiroz.

Colomy, P. (1998).

Neofunctionalim and neoinstitutionalism: human agency and interest in institutional change. Sociological Forum, 13(2), 265-300. 
Crubellate, J. M.,

Grave, P. S., \&

Mendes, A. A. (2004).

A questão institucional e suas implicações para o pensamento estratégico. Revista de Administração Contemporânea, 8(Edição Especial), 37-60.

Dacin, T.,

Goodstein, J., \&

Scott, W. R. (2002).

Institutional theory and institutional change: introduction to the special research forum. Academy of Management Journal, 45(1), 45-57.

DiMaggio, P. J. (1988).

Interest and agency in institutional theory. In L. Zucker (Ed.), Institutional patterns and organizations: culture and environment (pp. 3-21). Cambridge: Ballinger.

DiMaggio, P. J., \&

Powell, W. W. (1983).

The iron cage revisited: institutional isomorphism and collective rationality in organizational fields. American Sociological Review, 48(2), 147-169.

DiMaggio, P. J., \&

Powell, W. W. (1991).

Introduction. In W. W. Powell \& P. J. DiMaggio (Eds.), The new institutionalism in organizational analysis (pp. 1-38). Chicago: The University of Chicago Press.

Emirbayer, M., \&

Mische, A. (1998).

What is agency? American Journal of Sociology, 103(4), 962-1023.
Fligstein, N. (1985).

The spread of the multidivisional form among large firms, 1919-1979. American Sociological Review, 50(3), 377-391.

Fonseca, V. S. da, \&

Machado-da-Silva, C. L. (2002).

Conversação entre abordagens da estratégia em organizações: escolha estratégica, cognição e instituição. Organizações \& Sociedade, 9(25), 93-109.

Foucault, M. (1979).

Microfísica do poder. Rio de Janeiro: Edições Graal.

Giddens, A. (1978).

Novas regras do método sociológico. Rio de Janeiro: Zahar Editores.

Giddens, A. (1984).

The constitution of society. Berkeley: University of California Press.

Granovetter, M. (1985).

Economic action and social structure: the problem of embeddedness. American Journal of Sociology, 91(3), 481-510.

Hasselbladh, H., \&

Kallinikos, J. (2000).

The project of rationalization: a critique and reappraisal of neo-institutionalism in organization studies. Organization Studies, 21(4), 697-720.

Heracleous, L., \&

Hendry, J. (2000).

Discourse and the study of organization: toward a structurational perspective. Human Relations, 53(10), 1251-1286. 
Hinings, C. R., \&

Greenwood, R. (1988).

The dynamics of strategic change. New York: Basil Blackwell.

Hrebiniak, L. G., \&

Joyce, W. F. (1985).

Organizational adaptation: strategic choice and environmental determinism. Administrative Science Quarterly, 30(3), 336-349.

Jepperson, R. L. (1991).

Institutions, institutional effects, and institutionalism. In W. W. Powell \& P. J. DiMaggio (Eds.), The new institutionalism in organizational analysis (pp. 143-163). Chicago: The University of Chicago Press.

Lacey, H. (1998).

Valores e atividade científica. São Paulo: Discurso Editorial.

Machado-da-Silva, C. L., \&

Barbosa, S. L. de (2002).

Estratégia, fatores de competitividade e contexto de referência das organizações: uma análise arquetípica. Revista de Administração Contemporânea, 6(3), 7-32.

Machado-da-Silva, C. L., \& Fonseca, V. S. da (1993).

Estruturação da estrutura organizacional: o caso de uma empresa familiar. Organizações \& Sociedade, 1(1), 42-71.

Machado-da-Silva, C. L., \&

Fonseca, V. S. da (1996a).

Patterns of meaning: institutionalization and circumstances. In G. Palmer \& S. R. Clegg (Eds.), Constituting management: markets, meanings, and identities (pp. 139-153). Berlin: De Gruyter.
Machado-da-Silva, C. L., \&

Fonseca, V. S. da (1996b).

Competitividade organizacional: uma tentativa de reconstrução analítica. Organizações \& Sociedade, 4(7), 97 114.

Machado-da-Silva, C. L.,

Fonseca, V. S. da, \&

Fernandes, B. H. R. (2000).

Cognição e institucionalização na dinâmica da mudança em organizações. In S. B. Rodrigues \& M. P. Cunha (Orgs.), Estudos organizacionais: novas perspectivas na administração de empresas: uma coletânea luso-brasileira (pp. 123150). São Paulo: Iglu.

Machado-da-Silva, C. L., \&

Gonçalves, S. A. (2000).

Mudança organizacional, esquemas interpretativos e contexto institucional: dois casos ilustrativos. Revista de Estudos Organizacionais, 1(2), 11-26.

Meyer, J. W., \&

Rowan, B. (1977).

Institutionalized organizations: formal structure as myth and ceremony. American Journal of Sociology, 83(2), 340-363.

Misoczky, M. C. (2003).

Poder e institucionalismo: uma reflexão crítica sobre as possibilidades de interação paradigmática. In M. M. F. Vieira \& C. A. Carvalho (Orgs.), Organizações, instituições e poder no Brasil (pp. 141-175). Rio de Janeiro: Editora da FGV. 
Mizruchi, M. S., \&

Fein, L. C. (1999).

The social construction of organizational knowledge: a study of the uses of coercive, mimetic, and normative isomorphism. Administrative Science Quarterly, 44(4), 653-683.

Oliver, C. (1991).

Strategic responses to institutional processes. Academy of Management Review, 16(1), 145-179.

Oliver, C. (1992).

The antecedents of deinstitucionalization. Organization Studies, 13(4), 563-588.

Perrow, C. (1986).

Complex organizations: a critical essay. New York: McGraw-Hill.

Powell, W. W. (1991).

Expanding the scope of institutional analysis. In W. W. Powell \& P. J. DiMaggio (Eds.), The new institutionalism in organizational analysis (pp. 183-203). Chicago: The University of Chicago Press.

Ranson, S.,

Hinings, B., \&

Greenwood, R. (1980).

The structuring of organizational structures. Administrative Science Quarterly, 25(1), 1-17.

Roberts, P., \&

Greenwood, R. (1997).

Integrating transaction cost and institutional theories: toward a constrained-efficiency framework for understanding organizational design adoption. Academy of Management Review, 22(2), 346-373.
Scott, W. R. (1991).

Unpacking institutional arguments. In W. W. Powell \& P. J. DiMaggio (Eds.), The new institutionalism in organizational analysis (pp. 164182). Chicago: The University of Chicago Press.

Scott, W. R. (1994).

Institutions and organizations: toward a theoretical synthesis. In W. R. Scott \& J. W. Meyer and Associates, Institutional environments and organizations: structural complexity and individualism (pp. 55-80). London: Sage Publications.

Scott, W. R. (1995).

Introduction: institutional theory and organizations. In W. R. Scott \& S. Christensen (Eds.), The institutional construction of organizations (pp. xixxiii). London: Sage Publications.

Scott, W. R. (2001).

Institutions and organizations (2nd ed.). London: Sage Publications.

Scott, W. R.,

Ruef, M.,

Mendel, P. J., \&

Caronna, C. A. (2000).

Institutional change and healthcare organizations: from professional dominance to managed care. Chicago: The University of Chicago Press.

Selznick, P. (1992).

The moral commonwealth: social theory and the promise of community. Berkeley: University of California Press. 
Selznick, P. (1996). Institutionalism 'old' and 'new'. Administrative Science Quarterly, 41(2), 270-277.

Seo, M., \&

Creed, W. D. (2002).

Institutional contradictions, praxis and institutional change: a dialectical perspective. Academy of Management Review, 27(2), 222-247.

Sewell, W. H., Jr. (1992).

A theory of structure: duality, agency, and transformation. American Journal of Sociology, 98(1), 1-29.

Simon, H. A. (1979).

Comportamento administrativo. Rio de Janeiro: Editora da FGV.

Tolbert, P., \&

Zucker, L. G. (1996).

The institutionalization of institutional theory. In S. R. Clegg, C. Hardy, \& W. R. Nord (Eds.), Handbook of organization studies (pp. 175-190). London: Sage Publications.

Tsoukas, H., \&

Knudsen, C. (2002).

The conduct of strategy research. In A. Pettigrew, H. Thomas, \& R. Whittington (Eds.), Handbook of strategy and management (pp. 411435). London: Sage Publications.

Weber, M. (1998).

Economia e sociedade (R. Barbosa \& K. E. Barbosa, Trads.). (Vol. 2, 3a ed.). Brasília: Editora da UnB. (Obra original publicada em 1924).

Weick, K. (1969).

The psychology of organizing. Reading, MA: Addison-Wesley.

Weick, K. (1995).

Sensemaking in organizations. Thousand Oaks, CA: Sage Publications.

Weick, K. (2001).

Making sense of the organization. Malden, MA: Blackwell Publishing.

Whittington, R. (1988).

Environmental structure and theories of strategic choice. Journal of Management Studies, 25(6), 521-536.

Zilber, T. B. (2002).

Institutionalization as an interplay between actions, meanings, and actors: the case of a rape crisis center in Israel. Academy of Management Journal, 45(1), 234-254.

Zucker, L. G. (1987).

Institutional theories of organization. Annual Review of Sociology, 13, 443464.

Zucker, L. G. (1991).

The role of institutionalization in cultural persistence. In W. W. Powell \& P. J. DiMaggio (Eds.), The new institutionalism in organizational analysis (pp. 83-107). Chicago: The University of Chicago Press. 